\title{
Facile Preparation of ZnO Nanocatalysts for Ozonation of Phenol and Effects of Calcination Temperatures
}

\author{
Yuming Dong, ${ }^{\dagger,{ }^{\star *}}$ Hui Zhao, ${ }^{\dagger}$ Zhiliang Wang, ${ }^{\dagger}$ Guangli Wang, ${ }^{\dagger}$ Aizhen He, ${ }^{\dagger}$ and Pingping Jiang ${ }^{\dagger, *}$ \\ ${ }^{\dagger}$ School of Chemical and Material Engineering, Jiangnan University, Wuxi 214122, P. R. China \\ ${ }^{*}$ E-mail: dongym@jiangnan.edu.cn (Y. Dong),ppjiang@jiangnan.edu.cn (P. Jiang) \\ ${ }^{*}$ Key Laboratory of Environmental Engineering of Jiangsu Province, Jiangsu Academy of Environmental Science, \\ Nanjing 210036, P. R. China \\ Received August 24, 2011, Accepted November 21, 2011
}

\begin{abstract}
$\mathrm{ZnO}$ nanoparticles were synthesized through a facile route and were used as ozonation catalysts. With the increase of calcination temperature $\left(150-300^{\circ} \mathrm{C}\right)$, surface hydroxyl groups and catalytic efficiency of asobtained $\mathrm{ZnO}$ decreased remarkably, and the $\mathrm{ZnO}$ obtained at $150{ }^{\circ} \mathrm{C}$ showed the best catalytic activity. Compared with ozonation alone, the degradation efficiency of phenol increased above $50 \%$ due to the catalysis of $\mathrm{ZnO}-150$. In the reaction temperatures range from $5{ }^{\circ} \mathrm{C}$ to $35^{\circ} \mathrm{C}, \mathrm{ZnO}$ nanocatalyst revealed remarkable catalytic properties, and the catalytic effect of $\mathrm{ZnO}$ was better at lower temperature. Through the effect of tertbutanol on degradation of phenol and the catalytic properties of $\mathrm{ZnO}$ on degradation of nitrobenzene, it was proposed that the degradation of phenol was ascribed to the direct oxidation by ozone molecules based on solidliquid interface reaction.
\end{abstract}

Key Words : Zinc oxide, Calcination temperature, Surface texture, Catalytic ozonation

\section{Introduction}

Due to the growing population and the increasing pollution/contamination made by humankind, fresh water is becoming a critical limiting resource in the world. To solve this problem, advanced oxidation technology which can remove pollutants from wastewaters to reuse water is becoming an important topic of research. As a typical organic pollutant, phenol is one of the ubiquitous industrial wastewater contaminants. ${ }^{1}$ Because of the low degradation efficiency by microorganisms, phenol is considered highly toxic.

Currently, heterogeneous catalytic ozonation has received increasing attention due to its high efficiency in the degradation of refractory organic pollutants with low negative effect on water quality. ${ }^{2,3}$ The applications of catalytic ozonation to remove typical phenolic solutions demonstrated its promising prospect in water treatment. For example, commercial N-150 (Fe-Mn-O) catalyst revealed higher effect for biodegradability of a simulated phenolic wastewater. ${ }^{4}$ According to traditional catalytic ozonation theory, molecular ozone can oxidize organic substances via a direct route or can undergo decomposition via a chain reaction mechanism to produce free hydroxyl radicals.

With the development of nanoscience and nanotechnology, more and more researchers have focused on the application of nanomaterials for catalysts. On the one hand, nanomaterials have higher specific surface area and better dispersibility which were favorable for catalysis. On the other hand, nanomaterials could be synthesized with controllable sizes and morphologies so that the catalytic activity could be tuned. In our previous study, $\mathrm{Co}_{3} \mathrm{O}_{4}$ nanoparticles, ${ }^{5}$
$\alpha$-FeOOH nanorods ${ }^{6}$ and $\beta-\mathrm{MnO}_{2}$ nanowires ${ }^{7}$ were synthesized successfully, all of which showed better catalytic performances in the process of the ozonation degradation of phenol. At the same time, the surface properties have been proposed to be one of the major factors responsible for the catalytic activity of nanostructures. ${ }^{8,9}$

$\mathrm{ZnO}$ nanoparticles have been used in a wide range of applications including cosmetics, paints, plastics additives, ceramics and semiconductors. ${ }^{10}$ In addition, $\mathrm{ZnO}$ nanoparticles are considered as excellent candidates for heterogeneous ozonation catalysts due to high catalytic activity, non-toxicity, insolublity and cost-effectiveness. ${ }^{11-13}$ However, at present, most of the $\mathrm{ZnO}$ nanocatalysts used were acquired from commercial source and little is known about the influence of surface properties on catalytic properties in ozonation. In this work, a facile preparation route of $\mathrm{ZnO}$ nanocatalysts for ozonation of phenol was proposed firstly, then these nano- $\mathrm{ZnO}$ were used as model catalysts to elucidate the relationship between surface property and catalysis activity. We hope that this study may pave the way for understanding the relationship between surface property and catalysis activity, as well as find guidelines for the synthetic procedure to obtain efficient nanocatalyst with desired surface property.

\section{Experimental}

Materials. All chemicals used in this study were of analytical grade and were used without further purification. $\mathrm{Zn}\left(\mathrm{CH}_{3} \mathrm{COO}\right)_{2} \cdot 2 \mathrm{H}_{2} \mathrm{O}, \mathrm{NH}_{3} \cdot \mathrm{H}_{2} \mathrm{O}$, phenol and tert-butanol were purchased from Sinopharm Chemical Reagent Co. Ltd (China). All solutions were prepared with deionized water. 
Preparation of Catalysts. $\mathrm{ZnO}$ nanocrystals were prepared as reported by Zhao et al. ${ }^{14}$ with minor modification. $55.0 \mathrm{~g} \mathrm{Zn}\left(\mathrm{CH}_{3} \mathrm{COO}\right)_{2} \cdot 2 \mathrm{H}_{2} \mathrm{O}$ was dissolved in $500 \mathrm{~mL}$ deionized water in a beaker, then $\mathrm{NH}_{3} \cdot \mathrm{H}_{2} \mathrm{O}(6.0 \mathrm{~mol} / \mathrm{L})$ was added into the solution in a drop-wise manner under magnetic stirring until the $\mathrm{pH}$ of the mixture solution reached 10 . During this process, white precipitate formed slowly, then the precipitate dissolved gradually and the solution became clear again. The beaker was covered with filter paper and kept stirring for $72 \mathrm{~h}$, and then white precipitate gradually formed again. The precipitate was separated by filtration, washed with deionized water several times and dried for 12 $\mathrm{h}$ in an oven at $60{ }^{\circ} \mathrm{C}$. After this process, the precursors of $\mathrm{ZnO}$ formed. The obtained white powder was denoted as $\mathrm{ZnO}-\mathrm{P}$. $\mathrm{ZnO}-\mathrm{P}$ was divided into three parts, and each of them was put into a crucible and heated in a muffle furnace. The temperature was separately increased to 150,200 and $300{ }^{\circ} \mathrm{C}$ at a heating rate of $2{ }^{\circ} \mathrm{C} \mathrm{min}-1$ and kept for $2 \mathrm{~h}$, then cooled naturally. $\mathrm{ZnO}$ nanoparticles obtained at 150, 200 and $300{ }^{\circ} \mathrm{C}$ were dominated as $\mathrm{ZnO}-150, \mathrm{ZnO}-200$ and $\mathrm{ZnO}-300$, respectively.

Characterization and Analytical Methods. The composition and phase of the products were identified by powder X-ray diffraction (XRD) on an D8 X-ray diffractometer (Bruker AXS, German) using $\mathrm{Cu} \mathrm{K} \alpha$ radiation $(\lambda=1.5406$ $\AA)$. The morphologies and sizes of the products were examined by transmission electron microscopy (TEM) with a JEM-2100 (JEOL, Japan) transmission electron microscope at an accelerating voltage of $200 \mathrm{kV}$. The density of surface hydroxyl groups was measured according to a saturated deprotonation method. ${ }^{15}$ The specic surface area of the samples was measured according to the BrunauerEmmet-Teller (BET) method using nitrogen adsorption on a ASAP 2020 instrument (Micromeritics, USA) with the degas conditions of $110{ }^{\circ} \mathrm{C}$ for $3 \mathrm{~h}$. The concentration of phenol was determined by high-performance liquid chromatography (HPLC, WATERS, USA) with a UV absorbance detector (UV 2487). Absorbance intensity for phenol and nitrobenzene were set at the wavelength of $210 \mathrm{~nm}$ and 266 $\mathrm{nm}$, respectively. Elution was carried out by pumping methanol-water $(6: 4 \mathrm{v} / \mathrm{v})$ at a flow rate of $1.0 \mathrm{~mL} / \mathrm{min}$.

Catalytic Ozonation Process. The ozonation alone and catalytic ozonation were all carried out in a glass flask (250 $\mathrm{mL}$ ) equipped with gas inlet. Ozone produced from pure oxygen using a laboratory ozone generator was bubbled into the bottom of the flask at a rate of $0.50 \mathrm{mg} / \mathrm{min}$. In a typical catalytic ozonation, the simulated wastewater was prepared by spiking phenol in deionized water and the initial concentration of phenol was $100 \mathrm{mg} / \mathrm{L}$. $0.20 \mathrm{~g}$ catalyst was added into the $200 \mathrm{~mL}$ of the simulated wastewater and kept stirring for $10 \mathrm{~min}$ without ventilating ozone in order to reach the adsorption equilibrium of phenol on the catalysts. Then ozone was bubbled into the bottom of the flask and the catalytic ozonation was initiated with stirring under thermostatic control. At a certain time, samples were withdrawn for HPLC analysis. The ozonation alone were also conducted under similar conditions with that of catalytic ozone in the absence of the catalysts. In the ozonation process, the errors on residual concentrations of phenol were within $\pm 1.0 \mathrm{mg}$ / L.

\section{Results and Discussion}

Characteristics of ZnO Nanocrystals.

XRD Analysis of Catalysts: The crystalline phases of the as-obtained compounds were determined by X-ray diffraction (XRD). Figure 1 depicts the representative XRD patterns of $\mathrm{ZnO}-\mathrm{P}, \mathrm{ZnO}-150, \mathrm{ZnO}-200$ and $\mathrm{ZnO}-300$, respectively. It was showed that all the reflection peaks of $\mathrm{ZnO}-\mathrm{P}$ could be indexed as orthorhombic $\mathrm{Zn}(\mathrm{OH})_{2}$ (JCPDC Card No. 761778). All the diffraction peaks of $\mathrm{ZnO}-150, \mathrm{ZnO}-200$ and $\mathrm{ZnO}-300$ were consistent with those of $\mathrm{ZnO}$ with hexagonal wurtzite phases (JCPDS Card No. 80-0074). The peaks at diffraction angles of $2 \theta=31.8^{\circ}, 34.4^{\circ}, 36.3^{\circ}, 47.6^{\circ}, 56.6^{\circ}$, $62.9^{\circ}, 68.0^{\circ}$ and $69.1^{\circ}$ were ascribed to diffraction by basal planes $\{100\},\{002\},\{101\},\{102\},\{110\},\{103\},\{112\}$ and $\{201\}$, respectively. Diffraction peaks related to impurity were not observed in the XRD patterns, which confirmed the high purity of the synthesized products. The diffraction peaks of $\mathrm{ZnO}-300$ were more intensive and sharper than that of $\mathrm{ZnO}-200$ and $\mathrm{ZnO}-150$, indicating that calcination temperature could promote the crystallization of $\mathrm{ZnO}$ nanoparticles.

TEM Images: Transmission electron microscopy (TEM) was utilized to identify the morphologies and sizes of the products. Figure 2 illustrated typical TEM images of $\mathrm{ZnO}-\mathrm{P}$, $\mathrm{ZnO}-150, \mathrm{ZnO}-200$ and $\mathrm{ZnO}-300$, respectively. As shown in Figure 1(a), the morphology of $\mathrm{ZnO}-\mathrm{P}$ was hierarchy type structure which composed of many sheets with width and length about 200 and $500 \mathrm{~nm}$, respectively. All the $\mathrm{ZnO}$ samples were nanoparticles. The average diameters of $\mathrm{ZnO}-$ 150 ranged from 20 to $30 \mathrm{~nm}$, while the other two samples ( $\mathrm{ZnO}-200$ and $\mathrm{ZnO}-300)$ were in the range of 30 to $40 \mathrm{~nm}$. The results indicated that calcination temperature contributed to the growth of $\mathrm{ZnO}$ nanocrystals into larger particles to

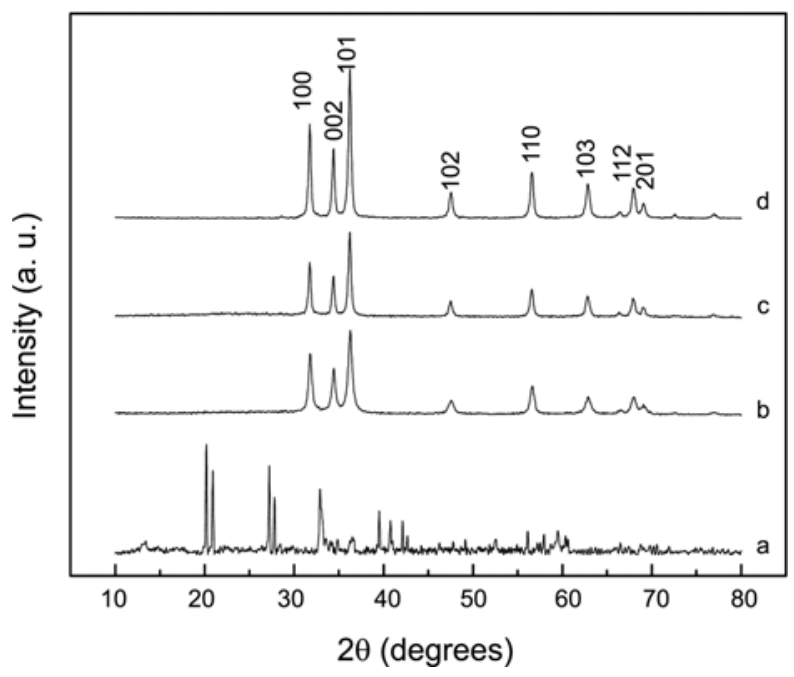

Figure 1. XRD patterns of ZnO-P (a), ZnO-150 (b), ZnO-200 (c) and $\mathrm{ZnO}-300(\mathrm{~d})$. 


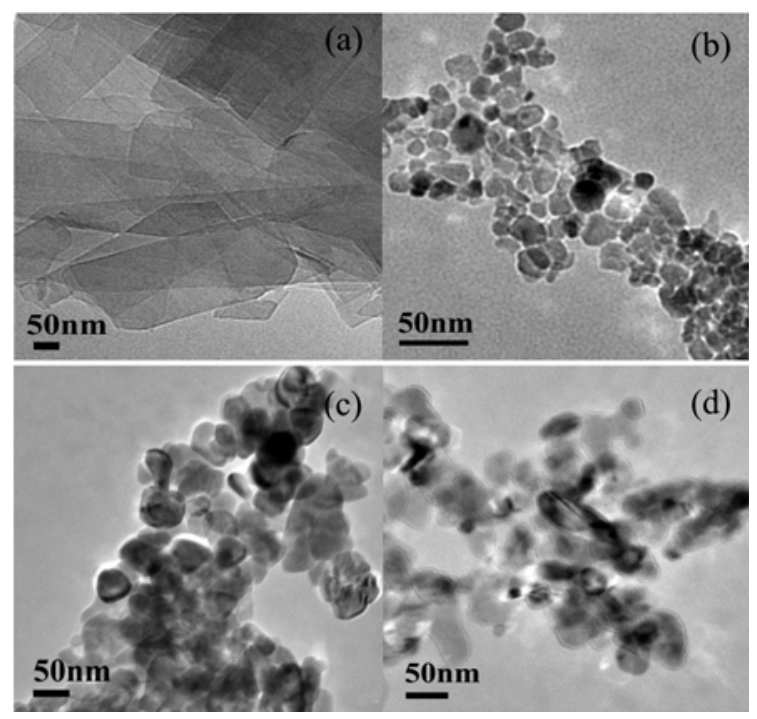

Figure 2. TEM micrographs of $\mathrm{ZnO}-\mathrm{P}$ (a), $\mathrm{ZnO}-150$ (b), $\mathrm{ZnO}-200$ (c) and $\mathrm{ZnO}-300$ (d).

Table 1. Surface characteristics of the $\mathrm{ZnO}$ nanocatalysts

\begin{tabular}{ccc}
\hline Catalysts & $\begin{array}{c}\mathrm{S}_{\mathrm{BET}} \\
\left(\mathrm{m}^{2} / \mathrm{g}\right)\end{array}$ & $\begin{array}{c}\text { Density of surface hydroxyl } \\
\text { groups }(\mathrm{mmol} / \mathrm{g})\end{array}$ \\
\hline $\mathrm{ZnO}-150$ & 11.22 & 1.0 \\
$\mathrm{ZnO}-200$ & 15.13 & 0.010 \\
$\mathrm{ZnO}-300$ & 14.34 & 0 \\
\hline
\end{tabular}

a certain degree.

Surface Characteristics: In heterogeneous catalytic ozonation, the surface characteristics of catalyst played an important role in its catalytic performance. ${ }^{16}$ The surface characteristics remarkably affected the adsorption reaction (ozone and organic pollutants adsorbed on the surface) and the mechanism of the catalytic ozonation. ${ }^{17}$ The surface characteristics including the specific surface area and density of surface hydroxyl groups are summarized in Table 1. According to the $\mathrm{N}_{2}$ adsorption-desorption isotherms

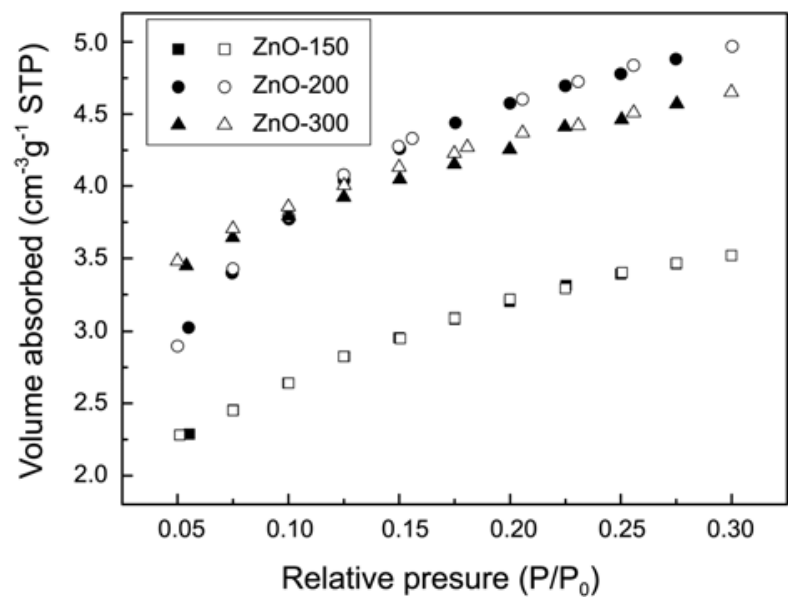

Figure 3. The $\mathrm{N}_{2}$ adsorption-desorption isotherms of $\mathrm{ZnO}-150$, $\mathrm{ZnO}-200$ and $\mathrm{ZnO}-300$ at standard temperature and pressure (STP).

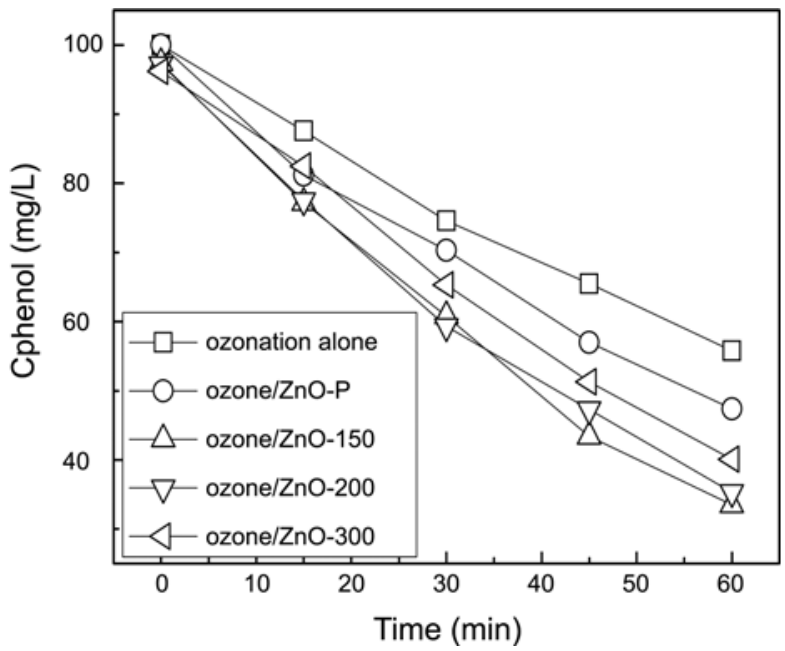

Figure 4. The degradation of phenol along with ozonation time in different processes. Experimental conditions: ozone dose: $0.50 \mathrm{mg} /$ min, catalyst dose: $1.0 \mathrm{~g} / \mathrm{L}$, initial phenol concentration: $100 \mathrm{mg} / \mathrm{L}$, $\mathrm{T}=20^{\circ} \mathrm{C}$.

shown in Figure 3, it was calculated that the $\mathrm{S}_{\mathrm{BET}}$ were $11.22,15.13$ and $14.34 \mathrm{~m}^{2} / \mathrm{g}$ for $\mathrm{ZnO}-150, \mathrm{ZnO}-200$ and $\mathrm{ZnO}-300$, respectively. With the increase of calcination temperature from $150{ }^{\circ} \mathrm{C}$ to $300{ }^{\circ} \mathrm{C}$, the density of surface hydroxyl groups of the products decreased rapidly: for example, it was $1.0 \mathrm{mmol} / \mathrm{g}$ for $\mathrm{ZnO}-150$ while it was 0.010 $\mathrm{mmol} / \mathrm{g}$ for $\mathrm{ZnO}-200$ and nearly zero for $\mathrm{ZnO}-300$.

Catalytic Ozonation of Phenol by ZnO Nanocrystals.

Influence of Calcination Temperature: The catalytic ozonation degradation of phenol using $\mathrm{ZnO}-\mathrm{P}, \mathrm{ZnO}-150$, $\mathrm{ZnO}-200$ and $\mathrm{ZnO}-300$ was investigated. The catalytic activities of all these samples were evaluated in comparison with ozonation alone. The results are shown in Figure 4. Only about $3-4 \mathrm{mg} / \mathrm{L}$ in the concentration of phenol were observed at 0 minute in the catalytic processes, which manifested that adsorption of phenol on the surface of the catalyst were too small to make a significant contribution to the remove of phenol from solution. Furthermore, it was found that the concentration of phenol decreased with increasing reaction time both in the ozonation alone and catalytic ozonation. Compared with $\mathrm{ZnO}-\mathrm{P}$ catalyst, all the calcined catalysts (ZnO-150, ZnO-200 and ZnO-300) dramatically improved the degradation efficiency of phenol in solution. Therefore, it could be concluded that through calcination of the precursors of $\mathrm{ZnO}$ in certain temperature, the ability for the elimination of phenol was accelerated.

In the presence of $\mathrm{ZnO}-150$, the decrement in the concentration of phenol was $66.5 \mathrm{mg} / \mathrm{L}$ after 60 minute. Under the same conditions, the decrements on concentration of phenol were $64.7 \mathrm{mg} / \mathrm{L}$ and $59.9 \mathrm{mg} / \mathrm{L}$ in presence of $\mathrm{ZnO}-$ 200 and $\mathrm{ZnO}-300$. Compared with ozonation alone, the degradation efficiencies of phenol were accelerated about $50.4 \%, 46.4 \%$ and $35.5 \%$ due to catalysis of $\mathrm{ZnO}-150$, ZnO200 and $\mathrm{ZnO}-300$, respectively. Obviously, the catalytic activity decreased for the products obtained with increased calcination temperature. The $\mathrm{ZnO}$ calcined at $150{ }^{\circ} \mathrm{C}$ show- 
ed the best catalytic activity. Therefore, $\mathrm{ZnO}-150$ nanocatalyst was employed for the latter research.

According to the above surface characteristics of the $\mathrm{ZnO}$ catalysts listed in Table 1, we can see that the density of surface hydroxyl groups positively correlated with the catalytic efficiency. It seemed that the density of surface hydroxyl groups was one of the essential factors affecting the catalytic property. Through the influence on density of surface hydroxyl groups, the increasing of calcination temperature from $150{ }^{\circ} \mathrm{C}$ to $300{ }^{\circ} \mathrm{C}$ revealed negative effect on catalysis.

At the same time, $\mathrm{ZnO}-300$ still revealed certain catalytic effect, though its density of surface hydroxyl groups was nearly zero. Therefore, it may be concluded that only partial catalytic effects come from surface hydroxyl groups. More catalytic effect may be due to other functional groups on surface of catalysts. The $\mathrm{S}_{\mathrm{BET}}$ value of $\mathrm{ZnO}-150$, $\mathrm{ZnO}-200$ and $\mathrm{ZnO}-300$ were $11.22,15.13$ and $14.34 \mathrm{~m}^{2} / \mathrm{g}$, respectively. It may be concluded that, the catalytic properties were synchronously influenced by many factors including density of surface hydroxyl groups and surface area, resulting in actual degradation efficiencies. All-around further investigations on the essential factors which influence catalytic activity are necessary in the next study.

Influence of Reaction Temperature: Reaction temperature was an important influential factor for ozone transformation, which was also significant for heterogenous catalytic ozonation. ${ }^{18}$ As a result, a series of experiments were carried out at different temperatures in the two processes (ozonation alone and catalytic ozonation). The influence of reaction temperatures on the degradation of phenol is shown in Figure 5.

In the process of ozone alone using $\mathrm{ZnO}-150$ for $60 \mathrm{~min}$, the decrement on concentration of phenol was accelerated from $55.1 \mathrm{mg} / \mathrm{L}, 66.5 \mathrm{mg} / \mathrm{L}$ to $84.0 \mathrm{mg} / \mathrm{L}$ with the increase of the reaction temperature from $5^{\circ} \mathrm{C}, 20^{\circ} \mathrm{C}$ to $35^{\circ} \mathrm{C}$. Obviously, an increase in degradation efficiency with the

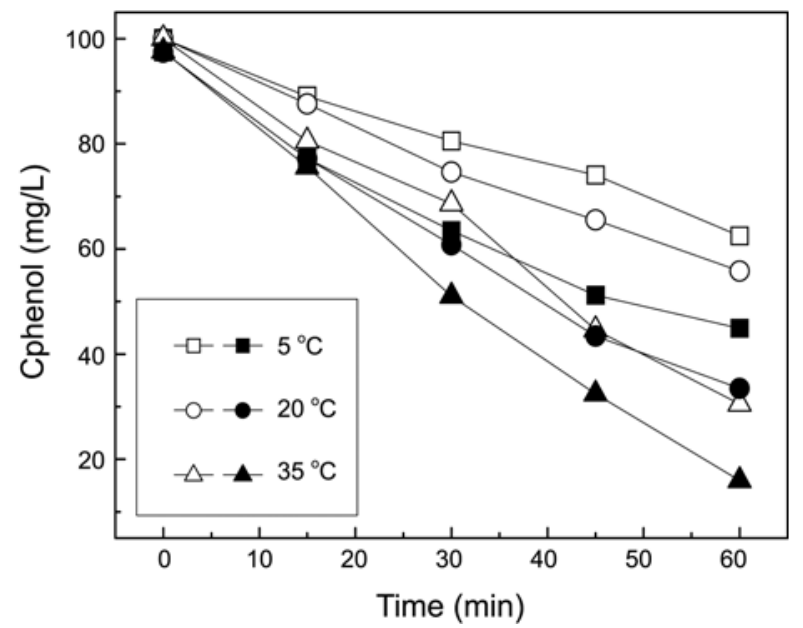

Figure 5. The degradation of phenol along with ozonation time at different reaction temperatures. The solid and hollow symbols stand for catalytic ozone using $\mathrm{ZnO}-150$ and ozone alone, respectively. Experimental conditions: ozone dose: $0.50 \mathrm{mg} / \mathrm{min}$, catalyst dose: $1.0 \mathrm{~g} / \mathrm{L}$, initial phenol concentration: $100 \mathrm{mg} / \mathrm{L}$. reaction temperature was observed. It was known that reaction temperature could influence the ozonation process in two aspects..$^{19}$ Firstly, the increase of temperature can promote the activation of ozone molecules, leading to the enhancement of the degradation efficiency. On the other hand, the increase of temperature also decreased the solubility of ozone in aqueous solution, resulting in a decrease in degradation efficiency. The two opposing effects work simultaneously, leading to a net increase in the degradation efficiency of phenol in ozonation alone and catalytic ozonation using $\mathrm{ZnO}-150$.

After ozonation for $60 \mathrm{~min}$ at $5{ }^{\circ} \mathrm{C}, 20^{\circ} \mathrm{C}$ and $35^{\circ} \mathrm{C}$, the decrements on concentration of phenol were $37.5 \mathrm{mg} / \mathrm{L}$, $44.2 \mathrm{mg} / \mathrm{L}$ and $69.5 \mathrm{mg} / \mathrm{L}$ in ozonation alone process, while those were $55.1 \mathrm{mg} / \mathrm{L}, 66.5 \mathrm{mg} / \mathrm{L}$ and $84.0 \mathrm{mg} / \mathrm{L}$ in catalytic ozonation. Due to the catalysis of $\mathrm{ZnO}$, degradation efficiencies of phenol increased about $46.9 \%, 50.4 \%$ and $20.9 \%$ at $5{ }^{\circ} \mathrm{C}, 20^{\circ} \mathrm{C}$ and $35^{\circ} \mathrm{C}$, respectively. That is to say, in the reaction temperatures range from $5{ }^{\circ} \mathrm{C}$ to $35^{\circ} \mathrm{C}, \mathrm{ZnO}$ nanocatalyst revealed remarkable catalytic properties, and the catalytic effect of $\mathrm{ZnO}$ was better at lower temperature.

\section{The Degradation Mechanism of Phenol.}

Influence of tert-Butanol on Degradation Efficiency of Phenol: Tert-butanol was a strong hydroxyl radical scavenger. The reaction rate constants of tert-butanol with hydroxyl radicals and ozone were $5.0 \times 10^{8} \mathrm{M}^{-1} \mathrm{~s}^{-1}$ and $3.0 \times 10^{-3}$ $\mathrm{M}^{-1} \mathrm{~s}^{-1}$, respectively. ${ }^{20}$ Tert-butanol easily reacted with hydroxyl radicals and generated inert intermediates, inhibiting the reaction between hydroxyl radicals and phenol. Consequently, the addition of tert-butanol in the catalytic ozonation system could enable us to evaluate whether aqueous free radicals participates in the catalytic ozonation.

In the experiment, $2.0 \mathrm{~g}$ tert-butanol was added to $200 \mathrm{~mL}$ of phenol solution, and the catalytic ozonation procedure was conducted as described in Experimental Section. As indicated in Figure 6, compared with normal catalytic ozonation using $\mathrm{ZnO}-150$, no significant difference in

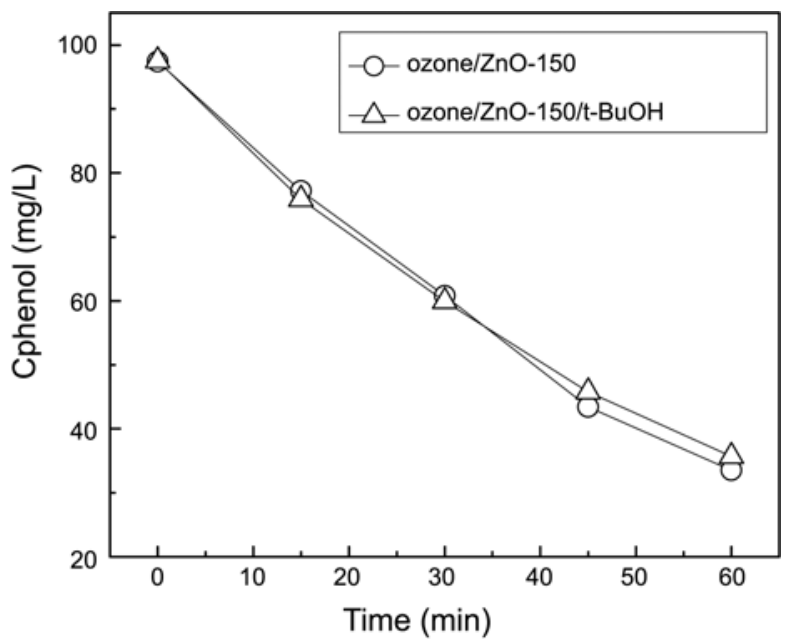

Figure 6. Effect of tert-butanol on the degradation of phenol in catalytic ozonation using $\mathrm{ZnO}-150$. Experimental conditions: ozone dose: $0.50 \mathrm{mg} / \mathrm{min}$, catalyst dose: $1.0 \mathrm{~g} / \mathrm{L}, t-\mathrm{BuOH}$ dose: $10.0 \mathrm{~g} / \mathrm{L}$, initial phenol concentration: $100 \mathrm{mg} / \mathrm{L}, \mathrm{T}=20^{\circ} \mathrm{C}$. 


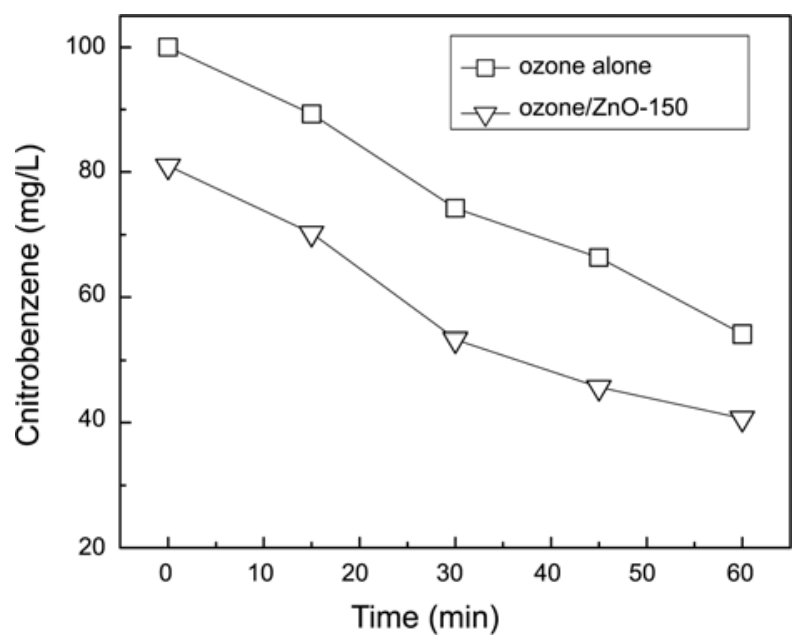

Figure 7. The degradation of nitrobenzene along with ozonation time in different processes. Experimental conditions: ozone dose: $0.50 \mathrm{mg} / \mathrm{min}$, catalyst dose: $1.0 \mathrm{~g} / \mathrm{L}$, initial nitrobenzene concentration: $100 \mathrm{mg} / \mathrm{L}, \mathrm{T}=20^{\circ} \mathrm{C}$.

phenol depletion was observed after adding tert-butanol. The results indicated that the degradation of phenol in the catalytic ozonation using $\mathrm{ZnO}-150$ probably did not follow the hydroxyl radical route in our current research.

Degradation Efficiency of Nitrobenzene: Nitrobenzene, an extremely nonbiodegradable organic pollutant, ${ }^{21}$ reacted slowly with molecular ozone but quickly with hydroxyl radicals. ${ }^{22}$ It was difficult for nitrobenzene to be oxidized by molecular ozone, while it could be easily oxidized by hydroxyl radicals. Therefore, nitotrobenzene was selected as another probe to evaluate the participation of hydroxyl radicals in the reaction.

As mentioned above, the $\mathrm{ZnO}-150$ catalyst and the reaction temperature of $20{ }^{\circ} \mathrm{C}$ were selected as the basic experimental conditions for the catalytic ozonation of nitrobenzene. The results are shown in Figure 7. It was found that the decrement in the concentration of nitrobenzene enhanced from $45.9 \mathrm{mg} / \mathrm{L}$ to $59.1 \mathrm{mg} / \mathrm{L}$ in catalytic ozone and ozone alone. However, about $20 \mathrm{mg} / \mathrm{L}$ of the total concentration of nitrobenzene was eliminated in catalytic ozone using $\mathrm{ZnO}$ 150 at 0 minute, which was attributed to the adsorption of nitrobenzene on $\mathrm{ZnO}-150$ nanocatalyst. The results demonstrated that the enhanced decrement in the concentration of nitrobenzene was mainly ascribed to the adsorption of nitrobenzene. The above results also demonstrated that the generation of hydroxyl radicals was not accelerated in presence of ZnO-150 nanocatalyst in our present study.

Possible Degradation Mechanism of Phenol: Ozone reacted with various organic and inorganic compounds in aqueous solution either by direct, selective reactions of molecular ozone or through a radical type reaction involving hydroxyl radicals induced by the decomposition of ozone in aqueous solution. ${ }^{23,24}$ Since, all the results pointed out that the degradation of phenol in aqueous solution could be attributed to the direct oxidation by ozone rather than following the indirect oxidation by hydroxyl radical in catalytic ozonation using $\mathrm{ZnO}-150$. Therefore, direct oxidation by ozone molecule should play a dominant role in the process. As it was discussed in section of influence of calcination temperature, a certain extent adsorption between phenol and the nano-catalyst surface existed, and the catalytic effects were influenced obviously by the surface properties. Hence, a mechanism based on reaction of solidliquid interface may be more possible. Both ozone molecule and phenol immigrate and concentrate on the surface of nanosized $\mathrm{ZnO}$, and the promoted oxidation reaction between ozone molecule and phenol will take place mainly at the solid-liquid interface.

\section{Conclusions}

Compared with ozone alone, the degradation of phenol was significantly increased in catalytic ozone using nano$\mathrm{ZnO}$. With the increase of calcination temperature from 150 to $300{ }^{\circ} \mathrm{C}$, the surface properties of the as obtained $\mathrm{ZnO}$ products were influenced obviously: the particle sizes and the crystallization enhanced, and the density of surface hydroxyl groups decreased. At the same time, the catalytic activity of $\mathrm{ZnO}$ nanoparticles decreased with increasing of calcination temperature, and the catalytic effect of $\mathrm{ZnO}$ calcined at $150{ }^{\circ} \mathrm{C}$ showed the best catalytic activity. In the reaction temperatures range from $5{ }^{\circ} \mathrm{C}$ to $35^{\circ} \mathrm{C}, \mathrm{ZnO}$ nanocatalyst revealed remarkable catalytic properties, and the catalytic effect of $\mathrm{ZnO}$ was better at lower temperature. Through investigating the effect of tert-butanol on the degradation efficiency of phenol and the catalytic properties of $\mathrm{ZnO}$ on degradation of nitrobenzene, it was found that the elimination of phenol was attributed to the direct oxidation by ozone molecules rather than by the hydroxyl radical. A mechanism based on reaction of solid-liquid interface may be more possible.

Acknowledgments. The authors gratefully acknowledge the support from the National Natural Science Foundation of China (No. 20903048 and 21005031), the Fundamental Research Funds for the Central Universities (JUSRP21113) and the Opening Foundation of the Key Laboratory of Environment Engineering of Jiangsu Province (No. KF2010004).

\section{References}

1. Moussavi, G.; Khavanin, A.; Alizadeh, R. Appl. Catal., B: Environ. 2010, 97, 160.

2. Lv, A. H.; Hu, C.; Nie, Y. L.; Qu, J. H. Appl. Catal., B: Environ. 2010, 100, 62.

3. Yang, L.; Hu, C.; Nie, Y. L.; Qu, J. H. Environ. Sci. Technol. 2009, $43,2525$.

4. Martins, R. C.; Quinta-Ferreira, R. M. Desalination 2011, $270,90$.

5. Dong, Y. M.; Wang, G. L.; Jiang, P. P.; Zhang, A. M.; Yue, L.; Zhang, X. M. Bull. Korean Chem. Soc. 2010, 31, 2830.

6. Dong, Y. M.; Yang, H. X.; He, K.; Wu, X.; Zhang, A. M. Appl. Catal., B: Environ. 2009, 85, 155.

7. Dong, Y. M.; Jiang, P. P.; Zhang, A. M. Chinese. J. Inorg. Chem. 2009, 25, 1595.

8. Liu, Z. Q.; Ma, J.; Cui, Y. H.; Zhang, B. P. Appl. Catal., B: Environ. 2009, 92,301

9. Song, S.; Liu, Z. W.; He, Z. Q.; Zhang, A. L.; Chen, J. M.; Yang, 
Y. P.; Xu, X. H. Environ. Sci. Technol. 2010, 44, 3913.

10. Li, M. H.; Pokhrel, S.; Jin, X.; Madler, L.; Damoiseaux, R.; Hoek, E. M. V. Environ. Sci. Technol. 2011, 45, 755.

11. Jung, H.; Choi, H. Appl. Catal., B: Environ. 2006, 66, 288.

12. Huang, W. J.; Feng, G. C.; Wang, C. C. Colloids Surf., A: Physicochem. Eng. Aspects 2005, 260, 45.

13. Zhai, X.; Chen, Z. L.; Zhao, S. Q.; Wang, H.; Yang, L. J. Environ. Sci. 2010, 22, 1527.

14. Zhao, B.; Wang, C. L.; Chen, Y. W.; Chen, H. L. Mater. Chem. Phys. 2010, 121, 1 .

15. Zhang, T.; Li, C. J.; Ma, J. Appl. Catal., B: Environ. 2008, 82, 131.

16. Qi, F.; Xu, B. B.; Chen, Z. L.; Ma, J.; Sun, D. Z.; Zhang, L. Q. Sep. Purif. Technol. 2009, 66, 405.

17. Zhang, T.; Ma, J.; Lu, J. F.; Chen, Z. L.; Li, C. J.; Jiang, J. Water
Sci. Technol.: Water Supply 2006, 6, 63.

18. Zhao, L.; Ma, J.; Sun, Z. Z.; Liu, H. L. J. Hazard. Mater. 2009, $167,1119$.

19. Beltrán, F. J.; Rivas, F. J.; Monter-de-Espinosa, R. Appl. Catal., B. Environ. 2002 39, 221.

20. Zhao, L.; Ma, J.; Sun, Z. Z. Appl. Catal., B: Environ. 2008, 79 , 244.

21. Mu, Y.; Yu, H. Q.; Zheng, J. C.; Zhang, S. J.; Sheng, G. P. Chemosphere 2004, 54, 789.

22. Zhao, L.; Ma, J.; Sun, Z. Z.; Liu, H. L. Appl. Catal., B: Environ. 2009, 89, 326.

23. Legube, B.; Karpel, V. L. N. Catal. Today 1999, 53, 61.

24. Kasprzyk-Hordern, B.; Zilek, M.; Nawrocki, J. Appl. Catal., B: Environ. 2003, 46, 639. 